\title{
O TRIBUNAL PENAL INTERNACIONAL PERMANENTE
}

\author{
José Roberto Franco da Fonseca \\ Professor Associado aposentado do Departamento de Direito \\ Internacional da Faculdade de Direito da Universidade de São Paulo
}

\begin{abstract}
Resumo:
Até julho de 1998, os crimes de guerra eram costumeiramente submetidos a tribunais "ad hoc" As primeiras cortes foram criadas pelos vencedores da II Guerra (Nuremberg e Tóquio); mais tarde, passaram a ser criadas por órgão imparcial: o Conselho de Segurança das Nações Unidas (Ruanda e Bósnia). Em julho de 1998, em Roma, Conferência Internacional criou o Tribunal Penal Internacional, de caráter permanente. A evolução da matéria, com isso, atingiu seu ponto máximo de aperfeiçoamento.
\end{abstract}

Abstract:

Until july 1998, war crimes were commonly treated by "ad hoc" courts. The earlier criminal courts were installed in Nuremberg and Tokyo by the Allies in World War II. Later on, courts addressing Rwandan and Bosnian issues were installed by an unbiased international entity, which is the Security Council of the United Nations. In july 1998, the International Conference in Rome installed the International Criminal Court, which is a permanent organization. At this point, the mechanisms of addressing international war crimes reached maximum advance.

Unitermos: Direito Internacional Penal; crimes de guerra; Tribunal Penal Internacional.

\section{Introdução}

Em 17 de julho de 1998, em Roma, a Conferência diplomática de plenipotenciários das Nações Unidas aprovou a criação de um Tribunal Penal Internacional, para julgamento dos crimes internacionais.

Foi importante passo, marcando definitivamente o processo de evolução do tratamento jurídico da matéria, hoje finalmente aperfeiçoada. Tal ocorre após décadas de exaustivas discussões e sucessivas reuniões da Conferência da ONU sobre prevenção da delinqüência e tratamento de delinqüentes (desde 1980), cujas 
origens remontam ao projeto elaborado pela Comissão de Direito Internacional das Nações Unidas (1954), seguido de projetos formulados pela Associação Internacional de Direito Penal (cf. nosso ensaio "Crimes de Guerra" in "Revista da Faculdade de Direito da USP" São Paulo, n. 93, 1998).

Tal evolução começou com a criação do primeiro tribunal eficiente em Nuremberg e Tóquio, em 1945, para julgar os criminosos de guerra do eixo. Tal Corte, prevista no Estatuto de Londres, era composta por juízes designados pelos Estados vencedores da Guerra e tal fato foi argüido como violador do princípio fundamental do juízo natural. Os dois tribunais de crimes de guerra que se the seguiram (ex-Iugoslávia, 1993; e Ruanda, 1994), sediados respectivamente na Holanda e na Tanzânia, foram criados não mais por Estados partícipes daquelas guerras: foram fruto de resolução do Conselho de Segurança da ONU. Resolvia-se o problema da imparcialidade e insuspeição (pressuposto processual de validade), embora o problema subsistisse quanto ao juízo de exceção.

A sociedade internacional, portanto, agora aperfeiçoa-se e tem atendidos seus anseios de legitimidade institucional, com a criação da Corte ocorrida em Roma.

As resoluções do Conselho de Segurança, por outro lado, vieram trazer importante inovação para a conceituação dos "crimes de guerra" estendendo sua abrangência para os delitos cometidos no interior do território estatal (nos casos de beligerância não-interestatal).

Mas a importância do Estatuto aprovado em Roma não para aí. Tal fonte, constituída de um preâmbulo e 128 artigos, não se limita a configurar a estrutura e funcionamento do Tribunal permanente (regulando aspectos relativos aos pressupostos processuais e condições da ação), mas, além disso, dispõe sobre temas substanciais de Direito Penal material (tipologia e estrutura dos crimes).

\section{Extensão e compreensão da jurisdição da Corte}

A jurisdição do Tribunal Criminal permanente será exercida tãosomente com relação à matéria objeto do Direito Internacional Penal. Portanto, restringir-se-á tal jurisdição aos "crimes internacionais", tipificados em fontes internacionais e cometidos por pessoas físicas partícipes de cenário de guerra (interestatal ou intestina). 
Excluem-se, assim, os chamados "crimes de caráter internacional" cuja subsunção dá-se no Direito Penal interno substancial (crimes tipificados no Direito Penal interno, para cuja execução o agente transita por territórios de dois ou mais Estados ou cujo "iter criminis" se desenrola por territórios de dois ou mais Estados, como o contrabando, o narcotráfico, o terrorismo, o tráfico de escravos ou mulheres, etc). Tais crimes de mero "caráter internacional" permanecem sujeitos às jurisdições penais internas dos Estados (e a respectiva distribuição internacional de competência para exercê-las, dentre os Estados interessados, é feita geralmente por convenções).

É louvável que a Conferência de Roma tenha assim agido. Havia temores generalizados, tendo em vista o encaminhamento da matéria tentado por grupos variados, que pudesse haver confusão quanto às duas categorias de delitos (a dos "internacionais" ou de guerra e a dos meramente "transnacionais").

\section{Estrutura e composição da Corte}

A Corte, sediada em Haia, tem personalidade jurídica de Direito Internacional e será vinculada à ONU por acordo que deverá ser aprovado por Assembléia dos Estados-Partes da convenção estatutária de Roma.

São órgãos da Corte: a. a Presidência; b. a Seção Preliminar, a Seção de Primeira Instância e a Seção de Apelação; c. o Gabinete do Procurador; d. a Escrivania.

A Corte é integrada por dezoito juízes, eleitos pela Assembléia dos Estados-Partes do Estatuto, a partir de listas organizadas pela mesma Assembléia, com nomes de candidatos indicados pelos Estados.

A Seção de Apelação é composta de um presidente e mais quatro juízes. A Seção de Primeira Instância e a Seção Preliminar são compostas de pelo menos seis juízes cada.

Os idiomas oficiais são o inglês, o francês, o russo, o espanhol, o chinês e o árabe. São línguas de trabalho, porém, o inglês e o francês, que serão usadas pelas partes durante o processo.

O mandato dos juízes é de nove anos e o presidente (assim como o $1^{\circ}$ e o $2^{\circ}$ vice-presidentes) é eleito por seus pares, por maioria absoluta, para um mandato de três anos. 


\section{Fontes}

No exercício de sua jurisdição, a Corte aplicará regras jurídicas que integrem um dos seguintes modelos: a. o Estatuto de Roma, que criou o Tribunal, e o Regulamento de Processo, Procedimento e Prova, a ser elaborado definitivamente pela Assembléia de Estados-Partes com observância dos princípios fundamentais adotados no próprio Estatuto; b. tratados aplicáveis e princípios de Direito Internacional (sobretudo os pertinentes à guerra e sua disciplina jurídica); c. os princípios gerais de Direito, verificáveis através do exame comparativo dos vários sistemas jurídicos; d. a jurisprudência da própria Corte, no atinente à interpretação das regras aplicáveis.

5. Procedimento, pressupostos processuais e condições da ação

Numa primeira fase (onde não existe ainda relação jurídica processual, mas tão-somente procedimento), a notitia criminis pode chegar ao procurador: a. por iniciativa de um Estado-Parte; b. por iniciativa do Conselho de Segurança da ONU nos termos do capítulo VII da Carta das Nações Unidas; c. por iniciativa de qualquer pessoa física ou jurídica.

Para a formulação, todavia, da acusação perante a Corte (demanda que fará nascer a relação jurídica processual), o procurador pode necessitar instaurar inquérito preliminar, que propiciará a formação de sua opinio, necessária à formalização da demanda. Tal abertura de inquérito, todavia, está sujeita a prévio controle jurisdicional: o procurador deve requerer autorização para instaurá-lo à Câmara Preliminar. Em caso de negativa de autorização, pode o procurador reiterar o pedido, desde que tenham surgido novas provas ou fatos. Por outro lado, a autorização concedida pela Câmara Preliminar não-impede a apreciação, por ocasião da propositura da demanda, dos pressupostos processuais e das condições da ação.

O iudicium accusationis será efetuado, assim, por ocasião da análise, por parte da Corte, da demanda em que o procurador, já tendo formado sua opinio, pedirá a instauração da ação penal. Tal iudicium accusationis, assim, repousará nãosó sobre pressupostos processuais e condições da ação, mas terá efeitos de verdadeira "pronúncia" dando abertura à fase iudicium causae.

Portanto, quanto à legitimidade ad processum (pressuposto processual de existência e validade da relação jurídica processual), o procurador tem-na, no 
pólo ativo. No pólo passivo, só pessoas físicas podem figurar como rés, pois se trata de "crimes", sabendo-se que o crime se estrutura com a configuração de três aspectos: tipicidade, antijuridicidade e culpabilidade (e o dolo, ínsito nesta última dimensão, é a consciência da antijuridicidade, função psicobiológica exclusiva do ser humano individualmente considerado).

Quanto ao pedido (pressuposto processual de existência da relação jurídica processual), é necessário que seja original (pressuposto processual de validade): o pedido não será admitido se a lide está sendo ou vai ser objeto de processo no território de algum Estado competente (art. 17. $\S 1^{\circ}$ alínea "a" do Estatuto de Roma); ou se a lide já foi composta, com trânsito em julgado (art. 17, § $1^{\circ}$, alíneas "b" e "c". do referido Estatuto).

Exigem-se, ainda, a insuspeição e imparcialidade de todos os juízes, diante de cada demanda (pressuposto processual de existência e validade do processo), admitindo-se, a respeito, exceção oponível por qualquer das partes (art. 41, do Estatuto).

Quanto às condições da ação, a possibilidade jurídica do pedido restringe-se à pretensão punitiva de restrição de liberdade física do réu, em caráter perpétuo ou temporário. $O$ interesse de agir apresenta, no Estatuto (art. 17、§ $1^{\circ}$ alínea "d"), original curiosidade: "Uma questão é julgada inadmissível pela Corte desde que (...) a questão não seja suficientemente grave para que a Corte the dê seguimento". Ora, em se tratando de crimes de guerra, parece-nos inadequada tal condição, uma vez que a persecução penal, nesses casos, só ocorre quanto a crimes dolosos, inexistindo os meramente culposos. O grau de gravidade do fato deveria ser apenas objeto de juízo, pela Corte, no momento processual de individualização judiciária da pena, que, como já foi dito, pode ser somente prisão, ou perpétua ou temporária, esta com o limite máximo de trinta anos, segundo estatuem os arts. 77 e 78 do documento analisado.

6. A matéria substancial contida no Estatuto. O Direito Internacional Penal

\subsection{Tipologia}

O Estatuto de Londres, de 8 de agosto de 1945, que criou o Tribunal de Nuremberg, tipificava, em seu art. $6^{\circ}$ três grupos de "crimes de guerra": a. "crimes contra a paz" (direção, preparação, desencadeamento ou prosseguimento de 
uma guerra de agressão ou de uma guerra de violação dos tratados, concertado ou em conluio para a execução de qualquer um dos atos precedentes); b. "crimes de guerra" em sentido estrito (violação de leis e costumes de guerra: assassinato, maustratos ou deportação para trabalhos forçados ou para qualquer outro fim, das populações civis dos territórios ocupados, assassinato ou maus-tratos dos prisioneiros de guerra ou náufragos, execução de reféns, pilhagem de bens públicos ou privados, destruição sem motivação estratégica de cidades ou aldeias ou devastações que as exigências militares não justifiquem); c. "crimes contra a humanidade" (assassinato, exterminação, redução à escravidão, deportação ou qualquer outro ato desumano cometido contra populações civis, antes e durante a guerra; ou então perseguições por motivos políticos, raciais ou religiosos, quando esses atos ou perseguições, quer tenham ou-não constituído violação do direito interno dos países onde foram perpetrados, hajam sido cometidos em conseqüência de qualquer crime que entre na competência do Tribunal ou em ligação com esse crime).

Os "crimes de guerra" em sentido estrito, agrupados em "b" no Estatuto de Londres acima referido, eram os que constituíam violações ao chamado "Direito Humanitário" compendiado em Genebra em 1864 e 1925, depois aperfeiçoado nas Convenções de ns. I, II, III e IV. de 1949. Quanto ao genocídio, subsumia-se no grupo dos "crimes contra a humanidade" A Convenção para a Prevenção e Repressão do Crime de Genocídio (Paris, 1948) tornava tal ilícito penalmente punível mesmo quando cometido em tempo de paz (art. $1^{\circ}$ ), tendo as partes contratantes assumido compromisso de inserir, em seus ordenamentos penais internos, o tipo penal respectivo (art. $5^{\circ}$ ).

Foi um tanto diversa a metodologia tipificadora adotada pelos convencionais de Roma, em 17 de julho de 1998.

Em Roma, adotaram-se quatro categorias de crimes internacionais, a saber: a. crime de genocídio (tipificado no art. $6^{\circ}$ ); b. crimes contra a humanidade (tipificados no art. $7^{\circ}$ ); c. crimes de guerra em sentido estrito (tipificados no art. $8^{\circ}$ ); d. crime de agressão (que em Londres se denominava "crime contra a paz" e que, no Estatuto de Roma, deixou de ser tipificado: tal tipificação caberá a uma Conferência das Partes Contratantes, a ser convocada pelo secretário geral da ONU, sete anos após a entrada em vigor do Estatuto de Roma).

Quanto ao crime de genocídio, duas inovações são feitas: a. o tipo passou a ser autônomo (com relação aos crimes contra a humanidade); b. passou-se 
a inserir na estrutura do tipo um elemento subjetivo-normativo: o dolo específico (a "intenção de destruir, no todo ou em parte, um grupo nacional, étnico, racial ou religioso"). E o núcleo do tipo (ação ou comissão por omissão) assim se enuncia: a. morte de membros do grupo; b. atentado grave à integridade física ou mental de membros do grupo; c. submissão do grupo a condições de existência que conduzam a sua destruição física, total ou parcial; d. prática de medidas visando a impedir nascimentos no seio do grupo; e. transferência forçada de crianças do grupo a um outro grupo.

Quanto aos crimes contra a humanidade (cometidos no "quadro de um ataque generalizado ou sistemático lançado contra uma população civil"), assim se tipificam: a. assassinato; b. extermínio; c. redução à escravidão; d. deportação ou transferência forçada de populações; e. aprisionamento ou outra forma grave de privação da liberdade física que viole as disposições fundamentais do Direito Internacional; f. tortura; g. estupro, escravidão sexual, prostituição forçada, engravidamento forçado, esterilização forçada e toda outra forma de violência sexual de gravidade comparável (tipo, pois, parcialmente em branco); h. perseguição de qualquer grupo ou qualquer coletividade identificada por motivos de ordem política, racial, nacional, étnica, cultural, religiosa ou sexual ou em função de outros critérios universalmente reconhecidos como inadmissíveis em Direito Internacional (aqui parece ter havido bis in idem, com relação à tipificação, agora autônoma, do crime de genocídio); i. desaparecimento forçado; j. apartheid; k. outros atos desumanos de caráter análogo que causem grandes sofrimentos ou atentados graves à integridade física ou à saúde física ou mental (aqui, infelizmente, equivocaram-se os elaboradores do Estatuto, pois a vagueza e amplitude da fórmula adotada não se compadece com a tipicidade, cujo fundamento é atribuir ao legislador, nunca ao juiz, a subsunção do fato ao tipo penal).

Os crimes de guerra em sentido estrito (atos ilícitos penais cometidos por beligerantes ou co-autores no cenário de conflito armado, interestatal ou intestino) são, no Estatuto de Roma (art. $8^{\circ}$ ), tipificados minuciosa e exemplarmente, mas, no seu todo, correspondem à tipificação elaborada pelos criadores do Tribunal de Nuremberg, em 8 de agosto de 1945. O Estatuto de Roma, de 1998, exclui do tipo, todavia, atos cometidos em um cenário de meras perturbações ou tensões internas (art. $8^{\circ}, \S 2^{\circ}$, alínea "d"); nesse caso, segundo o ensinamento de Marotta Rangel, não chega a se configurar "beligerância" senão mera "insurreição" 


\subsection{Estrutura dos crimes}

a. No plano da tipicidade

Sujeito ativo (agente) dos crimes tipificados no Estatuto de Roma é só o indivíduo. Agiram bem os legisladores, pois a responsabilidade penal é, por definição e em razão do plano da culpabilidade, abaixo analisado, personalíssima (art. 25). Encerrou-se assim, com correção técnica, longa discussão que permeou, durante décadas, as reuniões que tentavam, infrutiferamente, estabelecer, em tratado, os fundamentos do Direito Internacional Penal.

Sujeito passivo (titular ou portador do bem jurídico violado, cuja ofensa constitui a essência do crime, no dizer de Antolisei) é, sempre, a sociedade internacional (titular do interesse jurídico que se consubstancia no "ius puniendi" nascido com a prática da infração penal). Os indivíduos ou bens públicos sobre os quais se exerce a ação delituosa, nos crimes de guerra em sentido amplo, são objeto material da ação delituosa ("Handlungsobjekt"), pois, no caso, temos "delitos vagos" como denominam os juristas alemães os crimes que atingem um número indeterminado de pessoas ou bens ou princípios fundamentais da sociedade, estatal ou internacional.

Quanto à forma de tipificação adotada pelo Estatuto de Roma, ela é, em grande parte, aquela que Remo Pannain denominou "livre" (em oposição à "vinculada"): o verbo às vezes é reduzido a substantivo, estabelecendo tão-só a relação de causalidade que liga a ação ao resultado, como por exemplo: "apartheid" (art. $7^{\circ} \S 1^{\circ}$, alínea "j"), tortura (art. $7^{\circ}: \S 1^{\circ}$, alínea "f"), assassinato (art. $7^{\circ} \S 1^{\circ}$ alínea "a").

\section{b. No plano da antijuridicidade}

Se o objeto material da ação delituosa está contido na figura típica, o objeto substancial do crime diz respeito à antijuridicidade, pois se refere ao bem jurídico penalmente tutelado. A antijuridicidade pode ser apreciada do ponto de vista meramente formal (Costa e Silva entre nós, por exemplo), como oposição do fato típico ao ordenamento global; ou pode ser analisada do ponto de vista material (von Liszt: oposição ao bem comum; M.E. Mayer: oposição às normas de cultura). 
Se para Mayer a tipicidade é indício (ratio cognoscendi) da antijuridicidade, para Mezger ela é o fundamento real (ratio essendi) da antijuridicidade.

O dar início à agressão armada (guerra de conquista) já foi, no passado, considerado ato lícito (portanto, destituído de antijuridicidade). No século V, Santo Agostinho chegou a formular o conceito de "guerra justa" duzentos anos depois ampliado por Santo Isidoro de Sevilha e confirmado por Santo Tomás de Aquino, no século XIII. A formulação de tal conceito esteve na base da discussão teológica empreendida nas "Relectiones" por Francisco de Vitoria, a respeito do choque das armas de Espanha contra astecas e incas, sendo o pregador dominicano por isso considerado o pioneiro da cogitação de questões de Direito Internacional. Nas Conferências de Paz de Haia (1899 e 1907) as potências do Concerto Europeu e algumas jovens nações convidadas chegaram a estabelecer, por meio de convenções específicas, a regulamentação da guerra, bem como de aspectos de sua declaração e exercício. Diferentemente não dispôs o Pacto da Sociedade das Nações.

Todavia, em 1928, revolucionaram-se tais conceitos, com o Pacto Briand-Kellog: nesse documento, firmado originariamente por EUA e França, com adesão posterior de sessenta países (praticamente toda a comunidade internacional de então), passou-se a considerar a iniciativa da guerra como ato ilícito internacional. E a Carta da ONU, assinada em 26 de junho de 1945 , em seu art. $2^{\circ} \S$ $4^{\circ}$ proscreveu definitivamente a agressão armada contra a integridade territorial ou a independência política de qualquer Estado.

Portanto, o valor ínsito na norma penal internacional é a paz e a segurança (assim como a soberania estatal, igualdade dos Estados e dignidade da pessoa).

c. No plano da culpabilidade

No plano da culpabilidade penal, evoluiu-se da mera concepção psicológico naturalística (que poderia até ser suficiente para explicar a "vontade" ínsita no plano da tipicidade) para a moderna concepção normativa (Reinhard Frank, Freudenthal, Schmidt, Mezger): o dolo é concebido, hoje, como consciência da antijuridicidade. Não é outra a razão por que só pode ser agente de crime a pessoa física; "consciência" como ensina John Searle, de Berkeley, em publicação recente, é resultado de um processo neurobiológico, exclusivamente admissível no indivíduo. 
Por isso refere-se Jiménez de Asúa (p. 387) aos "elementos intelectuais" e "elementos afetivos" do dolo, para distingui-lo da mera vontade, que, esta sim, pode ter sua existência reconhecida pelo jurista (como ficção ou como realidade, pouco importa) na pessoa jurídica.

Dentre os crimes tipificados no Estatuto de Roma, os crimes de guerra em sentido estrito e os crimes contra a humanidade requerem dolo genérico. Já o genocídio (transformado em tipo autônomo) contém, já no próprio tipo, o que Frederico Marques e Jiménez de Asúa preferem chamar de "elemento subjetivo do tipo" (por não aceitarem a dicotomia entre dolo genérico e dolo específico): "com a intenção de destruir, no todo ou em parte, um grupo nacional, étnico, racial ou religioso" (art. $\left.6^{\circ}\right)$.

\subsection{Outros aspectos de Direito Penal substancial}

O Estatuto comina punibilidade à tentativa, mas considera excluída a tipicidade se houver desistência voluntária (art. $25, \S 3^{\circ}$, alínea " $\mathrm{f}$ "); deixa porém de fixar parâmetros para a individualização judiciária da pena no primeiro caso: fica ela inteiramente atribuída à eqüidade dos julgadores.

Quanto à punibilidade, o Estatuto afasta a possibilidade de eventual imunidade ser invocada por chefe de Estado ou de Governo, membro do Governo ou Parlamento, representante eleito ou agente governamental (art. 27), obviamente para o âmbito de jurisdição da Corte Internacional Penal. Quanto aos chefes militares, por outro lado, são responsáveis, em tese, por atos cometidos por seus subordinados, desde que, obviamente, presente o consentimento doloso (art. 28).

Os crimes sujeitos à jurisdição da Corte são imprescritíveis (art. 29).

Quanto à actio libera in causa, o Estatuto adotou (art. $31, \S 1^{\circ}$ : alínea "b") solução no mínimo discutível: o agente não é penalmente responsável se, no momento do fato, "ele estava em um estado de intoxicação que o privava de compreender o caráter criminoso ou a natureza do seu comportamento ou de conduzi-lo de modo a conformá-lo às exigências da lei, exceto se ele se intoxicou voluntariamente em circunstancias tais que o faziam saber que, pelo fato da intoxicação, ele estava assumindo o risco de vir a adotar o comportamento criminoso"

$\mathrm{O}$ agente que cumpre ordem de superior hierárquico (militar ou civil) não manifestamente ilegal tem o benefício da exclusão da antijuricidade (art. 33 , 
$1^{\circ}$ ), excetuados os casos de genocídio e crime contra a humanidade, em que se presume a manifesta ilicitude da ordem superior $\left(\operatorname{art} .33, \S 2^{\circ}\right)$.

\section{Conclusões}

A criação do Tribunal Penal Internacional permanente vem atender a antigo anseio da sociedade internacional, pois julgamentos de crimes internacionais vinham até então sendo feitos por tribunais ad hoc. Se é bem verdade que houve positiva evolução no sistema de constituição daqueles tribunais ad hoc (Nuremberg e Tóquio foram criados pelos beligerantes vencedores da II Guerra; Bósnia e Ruanda foram instituídos pelo imparcial Conselho de Segurança da ONU), não é menos verdade que a inexistência de órgão jurisdicional penal permanente e préconstituído, na sociedade internacional, de certa forma ofendia o princípio fundamental do juízo natural.

O Estatuto de Roma contém normas de natureza constitucional (na medida em que, além de ter criado a Corte, dispõe sobre sua estrutura e funções jurisdicionais, bem como atividades auxiliares), normas de caráter processual (na medida em que regula os pressupostos processuais e condições da ação, bem como o fluxo do procedimento) e normas de caráter penal substancial (na medida em que tipifica crimes internacionais e dispõe sobre elementos da estrutura desses crimes).

Quanto ao fato de o crime de agressão armada (crimes "contra a paz" na terminologia tradicional) não ter sido tipificado no Estatuto (sendo delegada tal função à Assembléia das Partes Contratantes a ser realizada, por convocação da Secretaria Geral da ONU, sete anos após a entrada em vigor da Convenção de Roma), é óbvio que, nesse ínterim, continua vigente a tipificação feita no Estatuto de Londres, de 8 de agosto de 1945.

São Paulo, março de 1999.

Bibliografia

ACCIOLY, H. e Silva, G. E. do Nascimento. "Manual de Direito Internacional Público" $12^{a}$ ed., São Paulo, Saraiva, 1996.

ASÚA, Luis Jiménez de. "La ley y el delito" $2^{\mathrm{a}}$ ed., Buenos Aires e México, Ed. Hermes, 1954. 
BASSIOUNI, Cherif M. "International Criminal Law", Nova York, Transnational Publishers Inc., 1986-7, 3 vs.

BRUNO, Aníbal. "Direito Penal". $4^{\mathrm{a}}$ ed., Rio, Forense, 1984, t. I.

CANÇADO TRINDADE, A. A. - "Direito das Organizações Internacionais" Brasília, Escopo Edit., 1990.

CARNELUTTI, Francesco. "Sistema del Diritto Processuale Civile" Padua, 1936, v. I, ns. 2-16.

CONOT, Robert. 'Justice at Nuremberg', Nova York, Harper \& Row, 1983.

COOPER, Robert W "The Nuremberg Trial", Nova York, Penguin, 1947.

FERREIRA, Ivette Senise. "Tutela penal do patrimônio cultural" São Paulo, Revista dos Tribunais, 1995.

FERREIRA JR., Geraldo Miniuci. "O Tribunal Criminal para a Iugoslávia" in "Solução e prevenção de litígios internacionais" (coord. Araminta de Azevedo Mercadante e José Carlos de Magalhães), São Paulo, Necin/Capes, 1998, pp. 93-128.

FONSECA, J. R. Franco da. "Crimes de Guerra" in "Revista da Faculdade de Direito da USP" São Paulo, 1998, n. 93.

GRINOVER, Ada P "As garantias processuais na cooperação Internacional em matéria penal". in "Direito Internacional no terceiro milênio (estudos em homenagem ao Prof. Vicente Marotta Rangel)" (coord. de Luíz Olavo Baptista e J. R. Franco da Fonseca), São Paulo, LTr, 1998, pp. 834-857.

GRINOVER, Ada P.; DINAMARCO, Cândido; ARAÚJO CINTRA, A.C. "Teoria Geral do Processo" 9a ed., São Paulo, Malheiros, 1992.

KARPETS, Igor. "Delitos de caracter internacional" trad. Pérez Castul, Moscou, Ed. Progreso, 1983.

LEWANDOWSKI, Enrique Ricardo. "Proteção dos direitos humanos na ordem interna e internacional" Rio, Forense, 1984.

LUNA, Everardo da Cunha. "Estrutura jurídica do crime" Recife, UFPe, 1970.

MAROTTA Rangel, Vicente "Solução pacífica de controvérsias: o impacto das organizações internacionais", in "Anuário Jurídico Interamericano" 1985 , pp. 29-48.

- "Direito e Relações Internacionais" $5^{\mathrm{a}}$ ed., São Paulo, Revista dos Tribunais, 1997

MELlo, Celso de Albuquerque. "Direito Penal e Direito Internacional" Rio, Freitas Bastos, 1978. 
- "Introdução ao estudo da sanção no Direito Internacional Público" Rio, Univ. Gama Filho, 1995.

PELLA. "La criminalité collective des États et le Droit Penal de l'avenir", Bucarest, Imprimérie de 1'État, 1926.

_. "La guerre-crime et les criminels de guerre", in "Revue de Droit International des sciences diplomatiques et politiques", Genebra-Paris, Ed. A. Pedone, 1943, pp. 63 e ss.

REALE JÜNIOR, Miguel. "Antijuridicidade concreta" São Paulo, J. Butshatsky, 1973.

—. "Teoria do Delito", São Paulo, Ed. Revista dos Tribunais, 1998.

REZEK, J. F. "Direito Internacional Público" São Paulo, Saraiva, 1989.

RIGAUX, François. "La compétence matérielle d'une Cour Criminelle internationale" in "O Direito Internacional no terceiro milênio (estudos em homenagem ao Prof. Vicente Marotta Rangel)"; coord. por Luiz Olavo Baptista e J. R. Franco da Fonseca), São Paulo, LTr, 1998, pp. 825-833.

RIPOLLÉS, Antonio Quintano. "Tratado de Derecho Penal Internacional e Internacional Penal" Madri, Inst. Francisco de Vitoria, 1955.

SMITH, Bradley F. "O Tribunal de Nuremberg", trad. de Henrique de Araujo Mesquita, Rio, Francisco Alves, 1979.

TAYLOR, Telford. "The anatomy of the Nuremberg Trials" Nova York, Knopf, 1992.

VIEIRA, Manuel A. "Derecho Internacional Penal y Derecho Penal Internacional" Montevideu, Fundación Cultura Universitaria, 1969.

WELZEL, Hans. "Derecho Penal alemán" trad. J. B. Ramirez e S. I. Perez, Santiago, Ed. Juridica, $3^{\text {a }}$ ed. espanhola, 1987. 